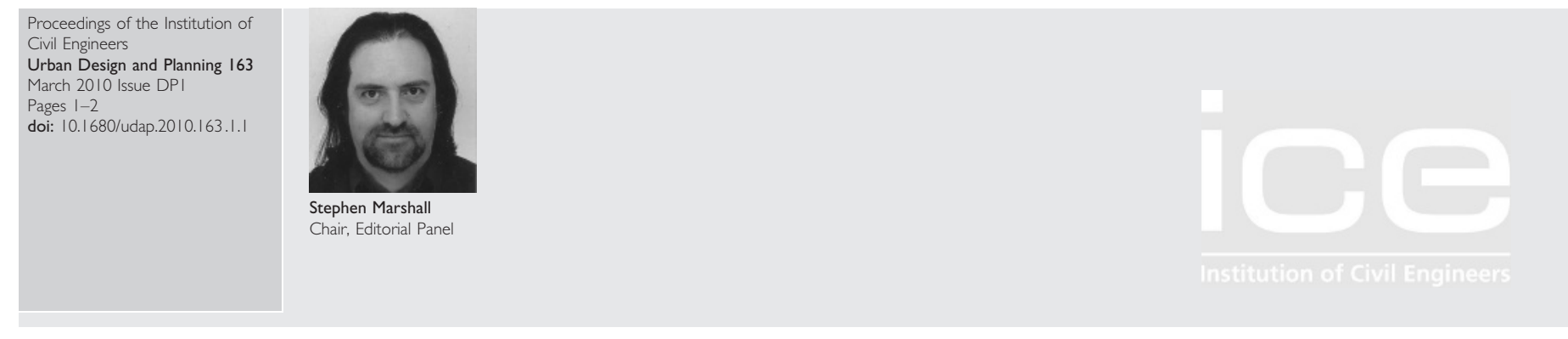

\title{
Editorial: Time for vision and reflection
}

\author{
S. Marshall BEng, DipUD, MSc(Eng), PhD, MCIT, MIHT
}

The upheavals of the recent global economic downturn have thrown up intriguing new perspectives from which to view the state of urban development. In a sense, the altered economic landscape that urban designers and planners find themselves operating within invites us to pause and question whether we are doing the right thing, and what other directions we might take in future. In other words, it seems like a good time for both vision and reflection.

Urban design and planning have always had a visionary aspect. The very words 'design' and 'plan' refer to visual representations. Of course, in the urban context, 'vision' is not just about perception of what is in front of us, nor simply anticipation of what might lie over the horizon; but the proactive conception of a desired future state. It is this normative, proactive aspect that can make urban design and planning creative and (sometimes) contested pursuits, over and above being purely technical disciplines.

Visionary urbanism usually connotes something bold, novel or radical - something, at any rate, that is more than simply a continuation of what went before. But being visionary is not just about dreaming up 'big plans' or 'grand designs'. It is also about having an eye for detail, being insightful about current uses and needs, seeing potential in the existing urban fabric and envisioning how a sense of place can be created out of a placeless void. The 'vision thing' is also about seeing things from different angles - not just from the point of view of one profession or interest group.

Urban Design and Planning aims to provide a platform for airing visions for future urban design and planning. This includes not only depictions of proposals for particular places or futuristic urban models, but also visions setting out future policy directions or agendas for the built environment professions themselves.

Starting with this issue, Urban Design and Planning intends to publish, periodically, dedicated 'visionary' articles that in one way or another will be agenda-setting, thought-provoking and suggestive of new horizons. In our inaugural article of this type, Kelvin Campbell (2010) argues evocatively that creating the 'big picture' need not just mean making a 'big splash' with extra large masterplans (XL), but could also be achieved through 'a million dabs' of extra small interventions (XS). He suggests that we need a new way of defining and regulating new development, in a fine grained approach based on the street - plot - block - building relationship. Campbell's take is visionary in the service of realising better places on the ground, not just for the sake of 'looking visionary' on plan.

A historical reflection on the 'novel and important' planning legislation of a century ago is then reported in Lester Hillman's briefing on John Burns' town planning act of 1909 (Hillman, 2010). This act was visionary in its day for promoting healthy homes and salubrious suburbs, while prohibiting back-to-back housing.

Subsequently in this issue, Granger (2010) takes stock of urban renewal and regeneration following the recent economic slowdown, and invites us to reflect critically on the policy principles and impacts of urban renewal projects. In the context of the transition from industrial to post-industrial cities, Granger argues that much of recent renewal and regeneration activity has had a limited impact on improving the lot of marginalised lower income groups, and suggests a more interventionist role for the public sector.

Meanwhile, Boyko et al., (2010) provide analysis and reflections on the urban design process. They create a baseline model of the urban design process, and compare this with a practical example of urban design in inner London, with particular attention to decision-making and sustainability. This paper in effect considers the process of urban design from the initial vision or goalsetting stage, through design to construction and monitoring. Considering all of these stages is, of course, necessary in order for an urban design vision to be successfully realised.

In addition to articles reporting original research, Urban Design and Planning also periodically publishes review articles, the primary intention of which is to provide a critical reflection and interpretation of a particular topic. The aim is to review current knowledge concisely from a breadth of sources, and distil messages of relevance for a broad, interdisciplinary audience. In this issue, Roitman (2010) provides a review of the literature on gated communities, and considers the economic, political and social consequences of what is now an increasingly significant format for urban development around the world.

\section{REFERENCES}

Boyko CT, Cooper R, Davey CL and Wootton AB (2010) Informing an urban design process by way of a practical example. Proceedings of the Institution of Civil Engineers, Urban Design and Planning 163(1): 17-30. 
Campbell K (2010) Making massive small change. Proceedings of the Institution of Civil Engineers, Urban Design and Planning 163(1): 3-6.

Granger R (2010) What now for urban regeneration? Proceedings of the Institution of Civil Engineers, Urban Design and Planning 163(1): 9-16.
Hillman L (2010) A 'Burns night' for planners. Proceedings of the Institution of Civil Engineers, Urban Design and Planning 163(1): 7-8.

Roitman S (2010) Gated communities: definitions, causes and consequences. Proceedings of the Institution of Civil Engineers, Urban Design and Planning 163(1): 31-38. 